\title{
Prevalence of headache among school children in Polonnaruwa educational zone
}

*K D Chamila Thushari Perera ${ }^{1}$, Jithangi Wanigasinghe ${ }^{2}$, Suneth Agampodi ${ }^{3}$, Udaya de Silva ${ }^{4}$

Sri Lanka Journal of Child Health, 2016; 45(3):199-203

\begin{abstract}
Objective: To determine the prevalence of primary headache among school children in the age group of 11-16 years in the Polonnaruwa educational zone.

Method: This was a school based cross sectional study. Study population was school children aged 1116 years in Polonnaruwa educational zone. A selfadministered questionnaire was used for screening. In those identified, a clinical examination and second questionnaire were used to collect further data. The diagnosis of migraine and tension type headache was based on the second edition of the International Headache Society's International Classification of Headache Disorders (ICHD II).
\end{abstract}

Results: A total of 683 students aged 11-16 years were invited to participate in this study out of which 606 responded $(88.5 \%)$. The median age of the study sample was 13 years (Interquartile range 12-15). There was a slight female predominance $(50.7 \%)$. Except for 32 (5.3\%) students, all others experienced headache at least once in their lifetime and 541 $(89.3 \%)$ had headache during past 12 months. Recurrent headache for at least for 3 months was reported by $39.8 \%$, and $86.4 \%$ (208) of them had presented at least once to the General Hospital Polonnaruwa for evaluation previously. After further

${ }^{1}$ Consultant Paediatrician, Base Hospital, Thabutthegama, ${ }^{2}$ Senior Lecturer and Consultant Paediatric Neurologist, Faculty of Medicine, University of Colombo, ${ }^{3}$ Consultant Community Physician, Head, Department of Community Medicine, Faculty of Medicine and Allied Sciences, Rajarata University of Sri Lanka, ${ }^{4}$ Consultant Paediatrician, Teaching Hospital Anuradhapura.

*Correspondence: chamilatp@gmail.com

(Received on 23 October 2015: Accepted after revision on 20 December 2015)

The authors declare that there are no conflicts of interest

Personal funding was used for the project.

Open Access Article published under the Creative

Commons Attribution CC-BY (CC) (P) evaluation, 194 students were found to have primary headaches and secondary causes were found in the balance 14 . The prevalence of migraine in this study sample was $7.8 \%$, with $53.2 \%$ having migraine with aura. The prevalence of tension type headache was $2.81 \%$. Majority $(67 \%)$ of the 194 with primary headache had unclassified headache. Migraine was more common among girls (9.1\%) compared to boys (6.4\%). However, this observed high prevalence was not statistically significant $(\mathrm{p}=0.204)$. Tension and unclassified headaches had no variation according to the age and sex.

Conclusions: Primary headaches occurred in $94 \%$ of children aged 11-16 years in the Polonnaruwa educational zone. The prevalence of migraine was $7.8 \%$.

DOI: http://dx.doi.org/10.4038/sljch.v45i3.8032

(Key words: Headache in children, migraine, tension type headache, Polonnaruwa educational zone, Sri Lanka)

\section{Introduction}

Headache is reported to occur in up to $25 \%$ of younger children and $75 \%$ of adolescents ${ }^{1}$ and the incidence has substantially increased over the last 30 years ${ }^{2}$. Recurrent headaches can negatively impact a child's life in several ways, including school absences, deterioration of academic performance, school stigma and impaired ability to establish and maintain peer relationships ${ }^{3,4}$. A study from Kashmir valley, India reported an overall prevalence of $664 / 1000$ of primary headache disorders in school children $^{5}$. A study performed in Taiwan showed that $85 \%$ of their children aged 13-15 years have had headaches ${ }^{6}$. No specific laboratory and radiological test establishes the diagnosis of primary headaches. Migraine is said to be the most common cause of primary headache in children ${ }^{7}$. Prevalence of migraine headache in the USA ranged from $1.2 \%$ $3.5 \%$ in 3 to 7 year old children, $4 \%-11 \%$ in 7 to 11 year old children and $8 \%-23 \%$ in adolescents ${ }^{7}$. In comparison, in the above study from India, the prevalence of migraine was as high as $27 \%{ }^{5}$. Reported annual prevalence rate for tension type headache (TTH) in Britain is $10-24 \%$. Though there 
are many studies about childhood primary headache internationally, there is no literature on prevalence of same in Sri Lankan children.

Polonnaruwa district is one of the largest agricultural areas in the dry zone of Sri Lanka located in the north central province. Borders of this district were significantly affected by terrorist activities for over 30 years before the end of the civil war in 2009 . Since then, the area has been undergoing rapid socioeconomic developments. The main income source of the people is agriculture which is affected intermittently by droughts and floods. Socioeconomic status of the residents in the community is exposed to frequent challenges. Childhood headache is a common presentation to the health care system in this region however; no systematic study has been conducted on its burden.

\section{Objective}

To determine the prevalence of primary headache among school children in the age group of 11-16 years in the Polonnaruwa educational zone.

\section{Method}

This was a school based cross-sectional study performed in the Polonnaruwa district. Study population was school children aged $11-16$ years. Schools which have classes up to year eleven in the Polonnaruwa educational zone, one of the two educational zones in Polonnaruwa district, was the study setting. Permission was obtained from zonal educational director, Polonnaruwa district and head masters of the relevant schools. The study was approved by the Ethics Review Committee, Faculty of Medicine and Allied Science, Rajarata University of Sri Lanka.

From the 25 secondary schools in the Polonnaruwa educational zone, a total of 683 school children (from grades 6-11) were randomly selected based on a calculated sample size, based on probability proportionate to size in sampling method. In this study, sample size was in proportion to the number of school children within 11-16 years in Polonnaruwa educational zone. All children were selected randomly without prior knowledge of their health or social background. The information sheet and consent form were distributed among the selected children. A self-administered questionnaire was distributed to those who obliged with consent. Children who were screened from this survey to have had recurrent headaches (at least for three months) and children who are currently under treatment for headache were invited to attend a specialized clinic at General Hospital Polonnaruwa.

When the children with headache were evaluated at the hospital by the paediatrician, a second questionnaire which is formulated on the basis of the International Headache Society criteria for the diagnosis of headache disorders ${ }^{9}$ was completed. All children were evaluated with a full systemic physical examination, including blood pressure measurement and a detailed neurological examination including ophthalmoscopy. All children were referred to the consultant ophthalmologist to exclude vision related cause for headache. Individuals found positive to have headache secondary to sinusitis or vision problems were excluded from the study.

Primary headaches were defined as those which develop by themselves and the causes are typically not known; the secondary headaches were defined as those which develop from an underlying illness or injury ${ }^{10}$. Primary headaches were categorized into four types according to the 2 nd edition of the classification from the International Headache Society: Migraine (with or without aura), TTH, trigeminal autonomic cephalalgias and other primary headaches ${ }^{9}$. Recurrent headaches were defined as those occurring over a period of at least three months ${ }^{11}$. The diagnosis of migraine and TTH was made based on criteria in ICHD II. 


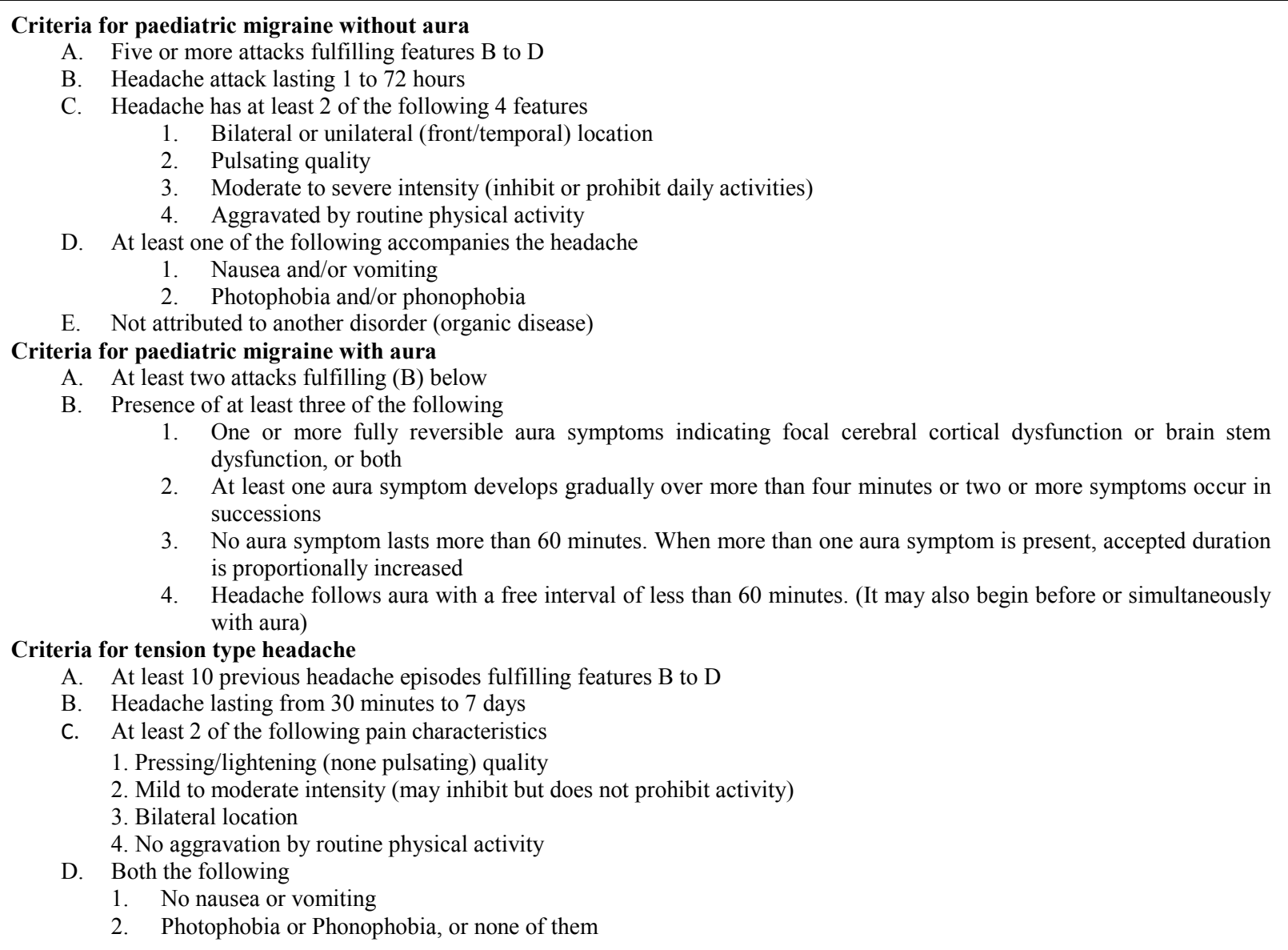

\section{Results}

A total of 683 students aged 11 - 16 years were invited to participate in the study. Six hundred and six responded to self-administered screening questionnaire ( $88.5 \%$ response rate). The median age of the study sample was 13 years (Interquartile range $12-15)$. Majority (50.7\%) were females. Six hundred and forty nine $(95 \%)$ stated that they had experienced at least one episode of disabling headache during their lifetime and of them $89.3 \%$ experienced the headache during the previous 12 months. From study sample, 241 (39.8\%) students have had recurrent headaches lasting at least for 3 months of whom 208 $(86.4 \%)$ had presented at least once to the regional hospital (Polonnaruwa) for evaluation.

Out of the 208 who had presented for evaluation, primary headaches were reported in 194 (93.3\%). The recurrent headaches were due to secondary causes in $14(6.7 \%)$. This included 8 with vision related problems, 4 related to sinusitis, and 2 being related to psychogenic causes. In the 194 with primary headaches, migraine type headache was experienced by $24.2 \%$. TTH was reported by $8.8 \%$.
Cluster headaches were reported by none. The headache in all other $67 \%$ was unclassifiable. Based on above percentages, the overall frequency of migraine in this population of school children between 11-16 years was 7.8\%. TTH occurred in $2.81 \%$. Headache was unclassifiable in $21.4 \%$. In the migraine group, $53.2 \%$ belonged to the category of migraine with an aura.

In the 194 students who were further investigated and followed up in our clinic, $63(32.5 \%)$ reported as having frequent headache (having headache at least once a week). Duration of headache was lasting less than 30 minutes in $75(38.7 \%)$ or $30-60$ minutes in 48 $(24.7 \%)$. The migraine type headaches was more common among girls $(9.1 \%)$ compared to boys $(6.4 \%)$. However, this observed high prevalence was not statistically significant $(p=0.204)$. TTH and unclassified headaches had no variation according to age and sex. 


\section{Discussion}

This population based study attempted to describe the prevalence of headache among the 11-16 year age group. Lifetime experience of significant headache was reported by $94 \%$. Primary headache accounted for $32 \%$; in whom migraine was reported in $24.2 \%$ and TTH in $8.8 \%$. Large majority of headaches were unclassifiable. Since there are no previous reports on prevalence of headache in Sri Lankan children, this study adds to better understanding of the disease burden and thereby better facilitation of available healthcare services in our country.

The prevalence rates of headaches in children are variable. In Jordan it accounted for $24 \%^{12}$ while in India it increased up to $66 \%{ }^{5}$. In Sweden, headache was reported in up to $39 \%$ of children aged 6 years, increasing to $70 \%$ by the age of 15 years ${ }^{13}$. Cause analysis of the recurrent headaches in children shows migraine to be the commonest cause of primary headache ${ }^{7}$. The reported frequencies include $17 \%$ in the $\mathrm{USA}^{4}$ and $10.6 \%$ in Scotland ${ }^{4}$. The lowest reported rates are 3\% from Hong Kong ${ }^{12}$ and 2.9\% from Jordan ${ }^{11}$. The worldwide prevalence of migraine in the adolescent population has been estimated to be around $4-10 \% 15,16$. The frequency of migraine among our study population was $7.8 \%$.

In relation to the different type of migraine, migraine without aura is the most frequent form of migraine in children and adolescents. It is reported to affect 60 $85 \%$ of cases $^{7}$. However, in our study sample, children with migraine with aura $(53 \%)$ were more than those with migraine without aura (47\%). Similar findings of higher proportion of children with migraine with aura $(53.1 \%)$ were reported among Jordanian children aged 6-14 years ${ }^{12}$.

Contrary to this understanding of migraine being the commonest type of primary headache, in some studies, prevalence of TTH outnumbered that of migraine. In Kashmir Valley, India, the estimated prevalence of TTH in school going children aged 818 years was $51 \%$ in comparison to $27 \%$ who suffered from migraine ${ }^{5}$. However, prevalence rates reported from Hong Kong for TTH was only $1.5 \%{ }^{17}$ and in Scotland was only $0.9 \%{ }^{14}$. Estimated prevalence of TTH in our study sample was also low with only $2.81 \%$ being affected. Significant differences in these values may be due to differences in the prevailing socioeconomic backgrounds, absence of conflicts and turmoil in these countries.

The majority of children with primary headache in our sample had headache which could not be classified $(67 \%)$ according to the criteria of the $2^{\text {nd }}$ edition of the International Headache Society. Short follow up duration is one possible reason why they did not get complete diagnostic criteria. Difficulty in obtaining a detailed history in children in comparison to adults is another explanation. Re-evaluating these children with the newer ICHD classification (2013) may help to differentiate the types of headache further ${ }^{18}$.

\section{Conclusions}

Primary headaches occurred in $94 \%$ of children aged 11-16 years in the Polonnaruwa educational zone. The prevalence of migraine was $7.8 \%$.

\section{Acknowledgements}

We acknowledge the contribution from Dr. K.R. Dayawansa, Consultant Eye Surgeon, General Hospital Polonnaruwa and his medical staff, staff of the paediatric unit at General Hospital Polonnaruwa, Dr. Jagath Ranasinghe, Senior House Officer attached to Paediatric Unit, Teaching Hospital, Anuradhapura, Zonal Director of Education and headmasters and teachers of schools in Polonnaruwa educational zone.

\section{References}

1. Hershey AD, Winner PK. Paediatric migraine: Recognition and treatment. Journal of the American Osteopathic Association 2005; 105(4): 52-60.

2. Anttila P, Metsahonkala L, Sillanpaa M. Long-term trends in the incidence of headache in Finnish schoolchildren. Paediatrics 2006; 117(6):1198-201. http://dx.doi.org/10.1542/peds.2005-2274 PMid: 16740819

3. Hershay AD. Headache In: Kliegman RM, Stanton BF, Behrman RE, editors. Nelson Textbook of Paediatrics $18^{\text {th }}$ ed. Philadelphia: Elsevier Saunders; 2011; p. 2039-46. http://dx.doi.org/10.1016/B978-1-43770755-7.00588-1

4. Lateef TM, Merikangas KR, He J, Kalaydjian A, Khoromi S, Knight E, et al. Headache in a national sample of American children: Prevalence and comorbidity. Child Neurology 2009; 24(5):536-43. http://dx.doi.org/10.1177/088307380832783 1

PMid: 19406755 PMCid: PMC2794247 
5. Malik AH, Shah PA, Yaseen Y. Prevalence of primary headache in school going children in Kashmir Valley. Annuals of Indian Academy of Neurology 2012; 15: 100-3.

http://dx.doi.org/10.4103/0972-2327.100030

PMid: 23024557 PMCid: PMC3444214

6. Lu SR, Fuh JL, Juang KD, Wang SJ. A student population based study in Taiwan. Cephalalgia 2000; 20; 479-86.

http://dx.doi.org/10.1046/j.14682982.2000.0

0076.x

PMid: 11037745

7. Lewis DW. Paediatric migraine. Neurologic Clinics 2009; 27(2): 481-501.

http://dx.doi.org/10.1016/j.ncl.2008.11.003

PMid: 19289227

8. Kernick D, Rainhold D, Campbell J L. Impact of headache on young people in a school population. British Journal of General Practice 2009; 59:678-81. http://dx.doi.org/10.3399/bjgp09X454142

PMid: 19674513 PMCid: PMC2734356

9. Headache Classification Subcommittee of the International Headache Society. The international classification of headache disorders, $2^{\text {nd }}$ edition. Cephalalgia 2004; 24 Suppl. 1:9-160.

10. Lopez JI, Rothrock JF. Headache, paediatric perspective. 2010. Available from: $\mathrm{http}: / /$ emedicine.medscape.com/article/2110 861-overview

11. McIntosh N, Helms PJ, Smith RL, Logan S, editors. Forfar and Arneil's Textbook of Paediatrics $7^{\text {th }}$ ed. 2009; 872-8. Available from: http://www.forfarandarneil.com/

12. Hussein FA, Hussein AB. Prevalence of headache and migraine among school children in Jordan. Sudanese Journal of Public Health 2006; 1(4): 307-8.
13. Bille B. Migraine in school children. A study of the incidence and short-term prognosis and a clinical, psychological and electroencephalographic comparison between children with migraine and matched controls. Acta Paediatrica. Supplementum 1962; 136: 1-151.

PMid: 13869189

14. Abu-Arefeh I, Russell G. Prevalence of headache and migraine in school children. British Medical Journal 1994; 309: 765-9. http://dx.doi.org/10.1136/bmj.309.6957.765 PMid: 7950559 PMCid: PMC2541010

15. Mortimer MJ, Kay J, Jaron A. Childhood migraine in general practice: clinical features and characteristics. Cephalalgia 1992: 12(4):238-43.

http://dx.doi.org/10.1046/j.14682982.1992.1 204238.x

PMid: 1525799

16. Linet MS, Stewart WF, Celentano DD, Ziegler D, Sprecher M. An epidemiologic study of headache among adolescents and young adults. Journal of the American Medical Association 1989; 261(15):2211-6. http://dx.doi.org/10.1001/jama.1989.034201 50061038

PMid: 2926969

17. Kong CK, Cheng WW, Wong L. Epidemiology of headache in Hong Kong primary level school children Hong Kong Medical Journal 2001; 7(1):29-45.

PMid: 11406673

18. Headache Classification Committee of the International Headache Society. The international classification of headache disorders, $3^{\text {rd }}$ edition (beta version). Cephalalgia 2013; 33(9):629-808 